\title{
BEHAVIOUR OF TRUCK'S COMPRESSOR'S CONNECTING RODS MADE OF ALUMINIUM ALLOY UNDER DIFFERENT MANUFACTURING CONDITIONS
}

\author{
Rasa Kandrotaitè-Janutienè \\ Dept of Production Engineering, Kaunas University of Technology, Lithuania \\ Submitted 22 January 2015; resubmitted 20 February 2015; accepted 17 April 2015; \\ first published online 15 June 2015
}

\begin{abstract}
The main objective of this study was to explore quality increasing and cost reduction opportunities for a production of forged aluminium alloy 6082 connecting rods. These automotive parts are used for air compressors' of the trucks. Connecting rods undergoes high cyclic loads during exploitation, therefore, the durability of this component is of a critical importance. The main factors characterizing high durability of the connecting rod are hardness and impact strength that may be achieved selecting the proper technology regimes. The main requirements for the aluminium alloy 6082 are hardness in the range of 90-120 HB and impact strength not less than $29.2 \mathrm{~J} / \mathrm{cm}^{2}$. Furthermore, the main problem is a stability of testing results of randomly picked connecting rods as these parts are produced in big quantities for the export purposes. Our experiments and recommendations for the development of technology of connecting rods' allowed maintaining the requirement in hardness, increasing the impact strength approximately twice and reducing the time needed for the production of one connecting rod as it let to save the cost of the part.
\end{abstract}

Keywords: air compressor; connecting rod; aluminium alloy; durability; impact strength; hardness.

\section{Introduction}

The manufacturers in automotive industry are continuously meeting challenges, such as improving fuel economy, enhancing performance, meeting customer desires, maintaining safety, quality and profitability and also meeting the legislative requirements.

Failure of vehicle components is an occurrence which affects peoples' safety. Components in vehicles, especially trucks, often operate under heavy load conditions, and in many cases, are required to perform without routine inspections. The failure of a component may result in nothing more severe than replacement of the damaged part. However, more catastrophic consequences may occur. The failure of any engine component may break a cylinder and may even destroy the whole engine (Yu, Xu 2015).

The connecting-rod is one of the important components of an automotive engine. The connecting-rod links the piston and the crankshaft and transfers the reciprocating motion of the piston into the rotary motion of the crankshaft. The main failure modes of connecting-rods are fatigue fracture, excessive deformation, and wear (surface fretting) (Pujatti et al. 2014). Improper manu- facturing includes design errors, defective heat treatment, raw material defects, machining defects, etc. (Yu, $\mathrm{Xu}$ 2015).

The connecting rod in truck's compressor (Fig. 1) plays essential role and this paper analyses the enhancement of its metallurgic properties. The connecting rods are subjected to a complex state of loading. These automotive parts are affected by high cyclic loads of an order of $10^{8}$ to $10^{9}$ cycles, which range from high compressive loads due to combustion, to high tensile loads due to inertia (Shenoy 2004).

Therefore, durability of these components is of a critical importance. Due to these factors, the connecting

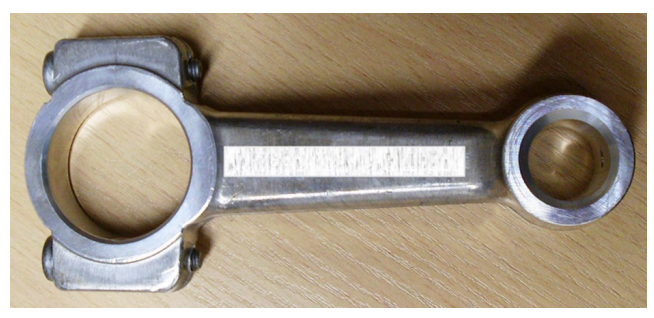

Fig. 1. Connecting rod 
rod has been the topic of research for different aspects, such as production technology, materials, performance simulation, fatigue, etc.

Aluminium offers a wide range of properties that can be engineered precisely to the demands of specific applications through the choice of alloy, temper and fabrication process (Davis 1999). The critical property of aluminium that makes it attractive is its low density $\left(2.69 \mathrm{~g} / \mathrm{cm}^{3}\right)$. Aluminium can be alloyed and strengthened by cold working and/or heat treatment to achieve high strength and so can achieve high strength to weight ratio. Aluminium castings and extrusions make it possible to consolidate product forms and functions, thereby reducing the number of components necessary to produce a vehicle and improving productivity (Benedyk 2010).

During thermo-mechanical treatment of aluminium alloys some specific material defects may occur coarse recrystallized areas clearly seen at the cross-cut (Fig. 2). a)

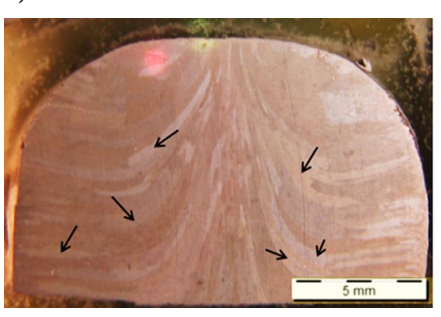

b)

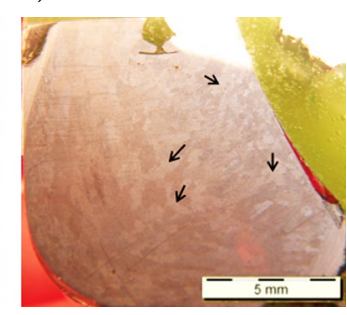

Fig. 2. Cross-cut of connecting rod, black arrows show coarse crystallized grains (light areas) at: a - longitudinal direction; $\mathrm{b}-$ transverse direction

Recrystallized areas are mostly observed in the surface layers that are in direct touch with the dies and/or in regions where local changes of plastic deformation take place. Recrystallized layers and areas in forgings have negative effect that the boundary between two different structures possessing remarkably different mechanical, fatigue and corrosion properties, is formed. It was found (Očenášek, Sedláček 2011) that recrystallized structure, in comparison with the unrecrystallized one, has lower values of ultimate strength (approximately by $70-90 \mathrm{MPa}$ ) and higher ductility (by 10\%). Furthermore, fatigue properties were obtained lower by one order in the case of recrystallized structure.

For the current study, it was necessary to investigate the main parameters of the connecting rod that allow maintaining required hardness and impact strength of the element. This was done by making developments in production technology that allowed not only to achieve high quality of the connecting rods but to reduce the cost of the production as well.

\section{Material and Methodology}

Material used for connecting rods production was an extruded profile of wrought aluminium alloy 6082 after T4 treatment. Chemical composition of alloy is listed in Table 1. Alloy 6082 used for production of connecting rods has to maintain the standard requirements before hot-work and heat treatment. These are presented in Table 2.

The final requirements for the connecting rods were determined by a customer and are shown in Table 3 .

Hardness of specimens was determined by measuring HRB values at three places of each specimen with Universal hardness meter VEZUS 750 under $100 \mathrm{kgf}$ loads.

Impact strength of the material was determined by Charpy impact testing machine using U-notched specimens made of semi manufactures (after thermomechanical treatment) (Žvinys et al. 2012).

The design of the assembled connecting rod containing the main dimensions is presented in the Fig. 3.

Water quenched and artificially aged connectingrods were turned to HRB hardness test at the flat surfaces of the major and minor heads. The cross-cuts for the metallographic research were made of the lower part of major head (Fig. 4a); macro and microstructure was investigated at the pointed places (Fig. 4b). Cross-cuts were cold mounted by the resin Technovit 4071, then grinded, polished with dough of chromium oxide and soup, and etched in $0.5 \%$ HF water solution. The macro and microstructure was examined by using the laser microanalyzer LMA10 Carl Zeiss with video camera YCH15.

Table 1. Chemical composition of EN-AW-6082-T4 certified SII-IQNet ISO 9001: 2008 No. 49937/10-2009, according to EN 573-515-755

\begin{tabular}{cc}
\hline Chemical element & Content, wt [\%] \\
\hline $\mathrm{Si}$ & 0.96 \\
\hline $\mathrm{Fe}$ & 0.17 \\
\hline $\mathrm{Cu}$ & 0.01 \\
\hline $\mathrm{Mn}$ & 0.46 \\
\hline $\mathrm{Mg}$ & 0.75 \\
\hline $\mathrm{Cr}$ & 0.003 \\
\hline $\mathrm{Zn}$ & 0.009 \\
\hline $\mathrm{Ti}$ & 0.021 \\
\hline $\mathrm{Al}$ & $\mathrm{Rem}$ \\
\hline
\end{tabular}

Table 2. Mechanical properties and requirements to extruded profile of alloy EN-AW-6082-T4 at $20^{\circ} \mathrm{C}$ temperature

\begin{tabular}{cccc}
\hline $\begin{array}{c}R_{m} \\
{[\mathrm{MPa}]}\end{array}$ & $\begin{array}{c}R_{p} 0.2 \% \\
{[\mathrm{MPa}]}\end{array}$ & $\begin{array}{c}\text { Elongation [\%] } \\
50 \mathrm{~mm}\end{array}$ & $\begin{array}{c}\text { Hardness } \\
{[\mathrm{HB}]}\end{array}$ \\
\hline \multicolumn{5}{c}{ Specified values } \\
\hline Min. & Min. & Min. & Min. \\
\hline 205 & 110 & 12 & - \\
\hline \multicolumn{5}{c}{ Measured values } \\
\hline $235-262$ & $121-146$ & $19-20$ & - \\
\hline
\end{tabular}

Table 3. The final requirements for connecting rod determined by a customer

\begin{tabular}{ccc}
\hline $\begin{array}{c}\text { Hardness } \\
{[\mathrm{HRB}]}\end{array}$ & $\begin{array}{c}\text { Impact strength } \\
{\left[\mathrm{J} / \mathrm{cm}^{2}\right]}\end{array}$ & $\begin{array}{c}\text { Features of } \\
\text { microstructure }\end{array}$ \\
\hline $54-65$ & More than 29.2 & $\begin{array}{c}\text { Fibrous without coarse } \\
\text { recrystallized grains }\end{array}$ \\
\hline
\end{tabular}



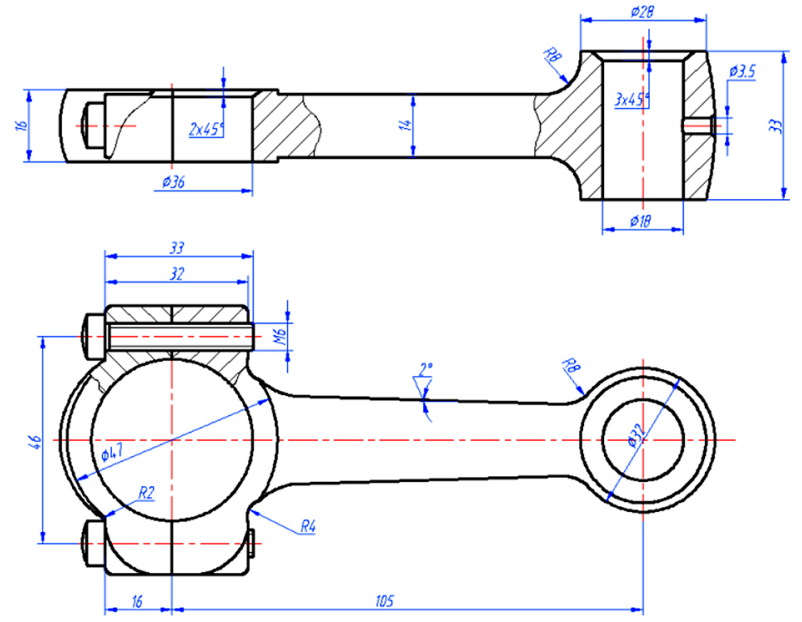

Fig. 3. Design of assembled connecting rod

a)

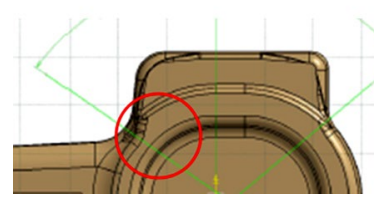

Fig. 4. Areas for micro and macro research at cross-cut of forging: $a$ - location for the samples preparing; $b$ - places

at the plane of cross-cut for the research of structure

Tests required heating were hold at laboratory chamber furnace Nabertherm N7/H/B150. Temperature of die forgings during plastic deformation was measured with laser thermometer. Temperature of the furnace was controlled by the device OMRON with chromel-alumel thermocouple.

\section{Analysis of the Initial Technology of Connecting Rods' Production}

The regimes of the manufacturing technologies discussed in this article were named as Regime A, Regime $\mathrm{B}$ and Regime C. Before the technology was improved, the producer used the Regime A for the manufacturing of the connecting rods. As the initial technology ( $\mathrm{Re}$ gime A) was not sufficient to achieve the requirements made by the customer to the quality of the connecting rods, the technology was started to improve and the Regimes $\mathrm{B}$ and $\mathrm{C}$ were created.

The initial technology Regime A of the connecting rod was as follows:

- double-hit forging of a workpiece heated till $500{ }^{\circ} \mathrm{C}$ temperature then cooled at still air;

- the forged workpiece was heated repeatedly up to $540{ }^{\circ} \mathrm{C}$ and quenched in the water of room temperature;

- the workpiece was artificially aged next day at $160{ }^{\circ} \mathrm{C}$ temperature for 12 hours.

The cross-cuts for metallography research and standard specimens for Charpy impact test were made for such thermo-mechanically treated connecting rods for the further investigation.
Hardness HRB test of the thermo-mechanically treated specimens showed high values in the range of 66-71 HRB. Optimal hardness range is 55-62 HRB, as when $\mathrm{HRB}<55$, machinability is getting worse.

Standard specimens made of such manufactured connecting rods showed very low impact strength values just in the range of $25-32 \mathrm{~J} / \mathrm{cm}^{2}$. The reason was revealed when the metallographic research was made that showed very coarse recrystallized grains (Fig. 5).
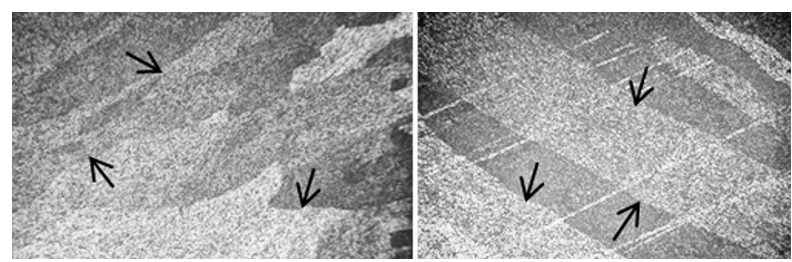

Fig. 5. Cross-cut of forging produced by Regime A (black arrows show the boundaries of coarse recrystallized grains)

\section{Influence of Intermediate Heating Between two Forging Hits on Requirements to the Structure}

For increasing the hardness, the temperature of forging and quenching was increased both up to $540{ }^{\circ} \mathrm{C}$. In addition, it was decided to quench the parts at once after forging operations. An intermediate heating between two forging hits was introduced in order to keep $540{ }^{\circ} \mathrm{C}$ temperature. Therefore, the Regime B of thermo-mechanical technology of connecting rods was as follows:

- workpiece was heated up to $540{ }^{\circ} \mathrm{C}$ then forged once;

- the forging was placed into the furnace for the intermediate heating for about 15 minutes at the temperature of $540{ }^{\circ} \mathrm{C}$, forged once more and rapidly cooled in the cold water;

- artificial ageing was performed next day at $180^{\circ} \mathrm{C}$ for 6 hours.

The specimens for metallographic research and impact strength tests were made of the connecting rods produced by Regime B technology. The results showed sufficiently high hardness in the range of $62-63 \mathrm{HRB}$ and values of impact strength of $37-38 \mathrm{~J} / \mathrm{cm}^{2}$. Therefore, the microstructure showed cracks (Fig. 6) at the surface of the most deformed area (Fig. 4b, point 2) at approximately $0.5 \mathrm{~mm}$ of depth. The microstructure was slightly recrystallized.

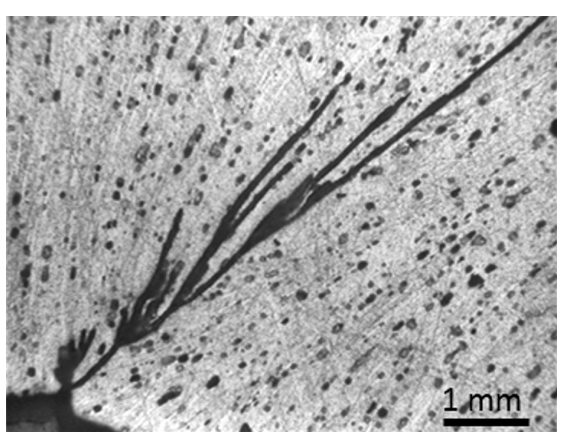

Fig. 6. Cross-cut of forging produced by Regime B showing cracks at the surface 
Probably the cracks were originated because of too high temperature as the optimal temperature for forging of aluminium alloys lies in the range of $400-500{ }^{\circ} \mathrm{C}$ but it is too low for precipitating hardening.

\section{Development of the Thermo-Mechanical Technology of Connecting Rods}

The further experiments showed that the intermediate heating before two hits of forging was not only unnecessary but also damaging as it evoked recrystallization.

However the temperatures of quenching and forging rest on different intervals, so, for the first, it was necessary to determine the optimal temperatures of quenching and plastic deformation and to match them introducing sub-cooling. The main criterion in selecting the optimal temperatures and duration of sub-cooling was the measuring of hardness HRB. The results are presented in Figs 7 and 8.

The results showed that the duration of sub-cooling has to be not longer than 20 seconds for all quenching temperatures of the experiment (Fig. 7) and the soaking time has to be not less than 45 minutes.

Talking of the most suitable temperature for quenching and for plastic deformation, Fig. 8 revealed that quenching from $540{ }^{\circ} \mathrm{C}$ gives sufficient hardness when the specimens are soaked not for less than $45 \mathrm{~min}-$ utes. Other papers also state that solution heat treatment is mostly performed at $530-550{ }^{\circ} \mathrm{C}$, followed by quenching to room temperature, to supersaturate the solid solution of alloy (Das et al. 2013; Scialpi et al. 2007; Kumar et al. 2014).
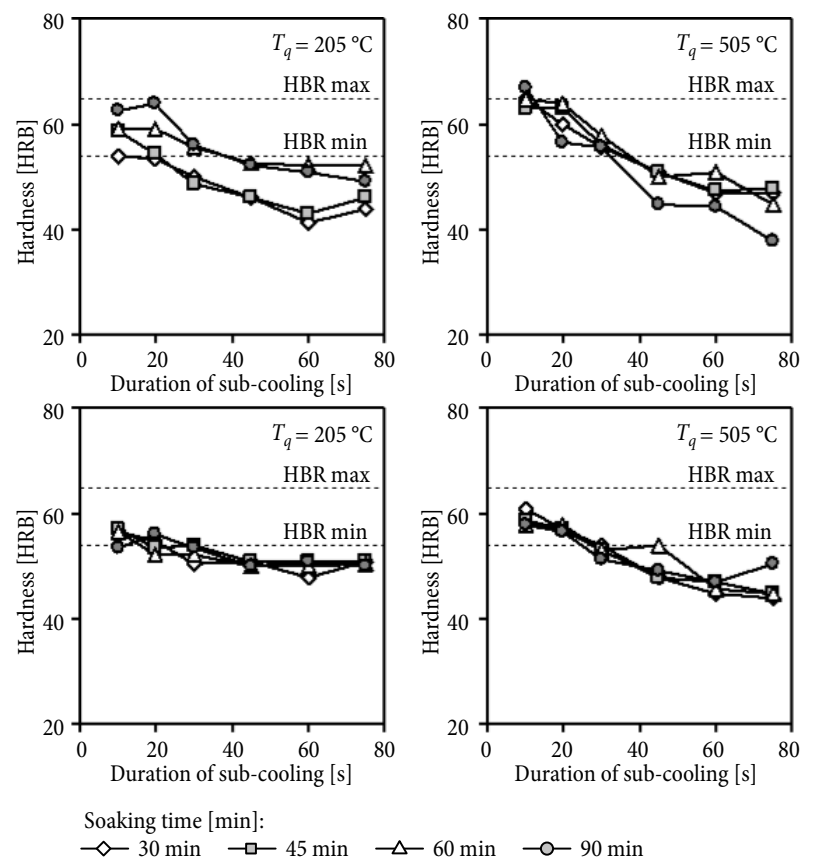

Fig. 7. Independence between duration of sub-cooling and hardness after quenching from different temperatures when the specimens were soaked $30,45,60$ or 90 minutes (quenching process was followed by artificial ageing at $160{ }^{\circ} \mathrm{C}$ for 16 hours)

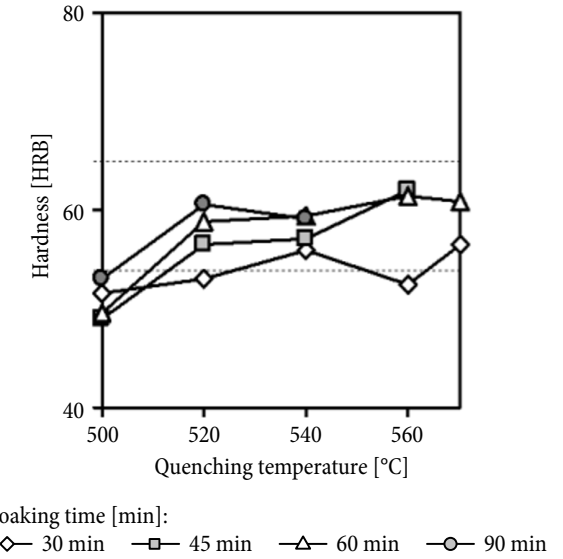

Fig. 8. Hardness of aluminium alloy 6082 after quenching from different temperatures (quenching process was followed by artificial ageing at $180^{\circ} \mathrm{C}$ for 6 hours)

According scientific papers the best values of yield limit and impact strength of aluminium alloy 6082 were achieved after artificial ageing at $175-190{ }^{\circ} \mathrm{C}$ temperature (Mrówka-Nowotnik et al. 2009) and it was enough less than 10 hours for getting the highest hardness (Mrówka-Nowotnik 2010).

Summarizing all findings, a new thermo-mechanical technology (Regime C) was designed containing the sequence of operations (Fig. 9):

- workpiece was heated up to $540 \pm 5{ }^{\circ} \mathrm{C}$ and soaked for $45 \mathrm{~min}$ in the dry air ambience;

- sub-cooled in the air until the temperature drops to $490 \pm 5{ }^{\circ} \mathrm{C}$ while the workpiece is placed into dies (this takes about $1 \mathrm{~min}$ and $20 \mathrm{~s}$ );

- double-hit forging;

- rapid water cooling at $40 \pm 20^{\circ} \mathrm{C}$ temperature;

- artificial ageing at $180 \pm 5{ }^{\circ} \mathrm{C}$ temperature for 6 hours but not later than after 10 hours;

- final air cooling.

A series of the connecting rods was produced according the Regime C. The specimens for Charpy test and metallographic analysis were made of the shanks of

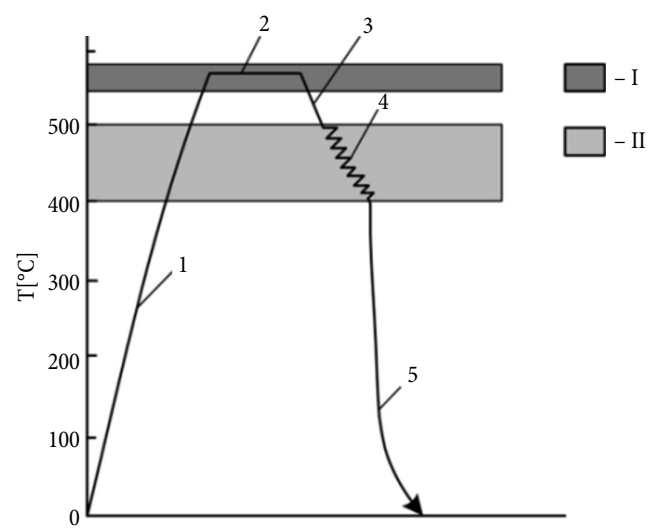

Fig. 9. A part of Regime C illustrating thermo-mechanical technology of connecting rods': 1 - heating; 2 - soaking; 3 sub-cooling; 4 - forging; 5 - water cooling (temperature ranges: I - interval of quenching; II - interval of plastic deformation) 
the connecting rods. The values of impact strength were obtained more than twice higher comparing to those determined after Regime A. The results of the measurement of impact strength are listed in the Table 4. Dispersion of the impact strength values is presented in the Fig. 10.

The hardness lied in the required interval, i.e. it was 58-62 HRB. The microstructure (Fig. 11) of the crosscuts didn't show any big recrystallized grains, it was fibrous because of hot plastic deformation and appeared to be a reason of high values of impact strength. Just small origins of the recrystallization process were observed, but they didn't have any significant influence on the strength and durability of the connecting rods. Any cracks were detected, so, high requirements for connecting rods made by the customer were fulfilled.

Development of the thermo-mechanical treatment of connecting rods allowed not only implementation of the requirements to quality made by a customer, but also saved the cost of energy used for heating operations. It was calculated, that if the furnace operates using $30 \mathrm{~kW}$ energy and works at least 16 hours per day with the energy using coefficient of 0.5 , the producer

Table 4. The results of impact strength measurement

\begin{tabular}{ccccc}
\hline \multirow{2}{*}{ Quantity } & Min & Max & Average & Deviation \\
\cline { 2 - 5 } & \multicolumn{5}{c}{$\left[\mathrm{J} / \mathrm{cm}^{2}\right]$} \\
\hline 57 & 56.2 & 90.6 & 76.6 & 4.99 \\
\hline
\end{tabular}

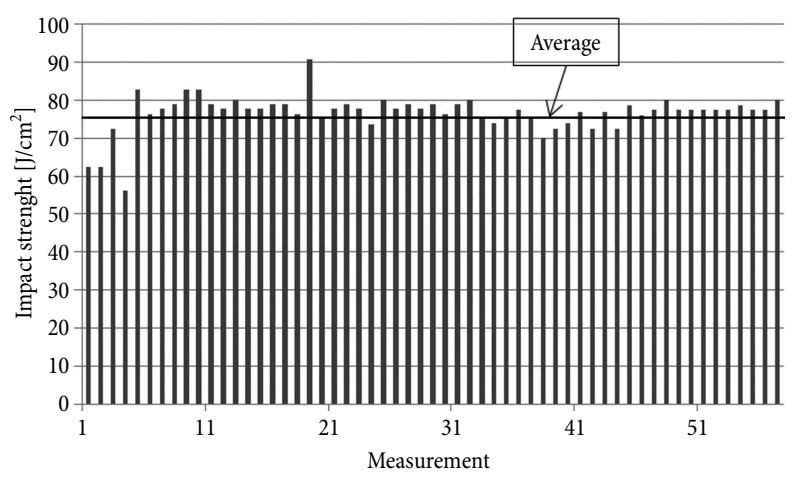

Fig. 10. A dispersion of the measurement of impact strength values of aluminium connecting rods

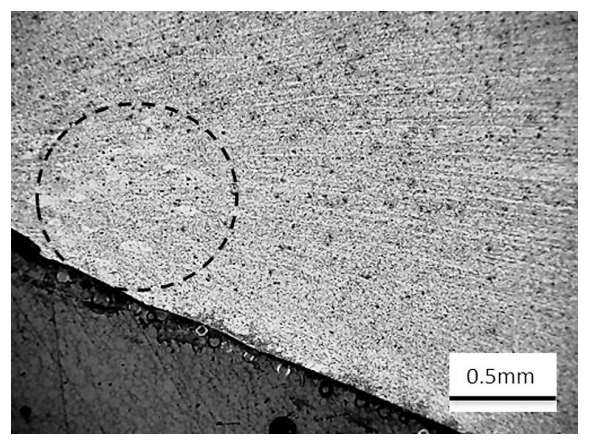

Fig. 11. Microstructure of the specimen produced according Regime C technology (the dashed circle shows small brighter areas - the origins of recrystallization) may save approximately 10000 EUR/year. The quantity of production may be increased as the time required for manufacturing of one connecting rod becomes shorter.

\section{Conclusions}

Development of the thermo-mechanical technology of the connecting rods made of aluminium alloy 6082 led to the advantages of mechanical properties of the vehicle components maintaining safety, durability and lower cost of manufacturing:

1. mechanical properties of the workpiece were developed as ultimate strength was increased up to $25 \%$ and impact strength became at least twice higher comparing to the values of impact strength obtained for the connecting rods produced according the former technology and this was resulted by fibrous and not recrystallized microstructure;

2. sufficient hardness was obtained - in the range of 58-62 HRB, as lower hardness may lead to the deformation of the component and higher - to the brittle fracture;

3. no cracks were detected at the surface of the bent places of the connecting rods that may cause fatigue fracture of the component;

4. energy savings were made. It was calculated that refusing of one heating of a set of connecting rods let saving approximately $10000 \mathrm{EUR} /$ year.

\section{References}

Benedyk, J. C. 2010. Aluminum alloys for lightweight automotive structures, in P. K. Mallick (Ed.). Materials, Design and Manufacturing for Lightweight Vehicles 3: 79-113.

http://dx.doi.org/10.1533/9781845697822.1.79

Das, S.; Pelcastre, L.; Hardell, J.; Prakash, B. 2013. Effect of static and dynamic ageing on wear and friction behavior of aluminum 6082 alloy, Tribology International 60: 1-9. http://dx.doi.org/10.1016/j.triboint.2012.10.019

Davis, J. R. 1999. Corrosion of Aluminum and Aluminum Alloys. ASM International. 313 p.

ISO 9001:2008. Quality Management Systems - Requirements.

Kumar, V.; Singh, I. V.; Mishra, B. K.; Jayaganthan, R. 2014. Experimental investigation of fatigue behavior of CR and RTR 6082 Al-alloy, Procedia Materials Science 6: 1919-1926. http://dx.doi.org/10.1016/j.mspro.2014.07.225

Mrówka-Nowotnik, G. 2010. Influence of chemical composition variation and heat treatment on microstructure and mechanical properties of 6XXX alloys, Archives of Materials Science and Engineering 46(2): 98-107.

Mrówka-Nowotnik, G.; Sieniawski, J.; Nowotnik, A. 2009. Effect of heat treatment on tensile and fracture toughness properties of 6082 alloy, Journal of Achievements in Materials and Manufacturing Engineering 32(2): 162-170.

Očenášek, V.; Sedláček, P. 2011. The effect of surface recrystallized layers on properties of extrusions and forgings from high strength aluminium alloys, Proceedings of the 20th Anniversary International Conference on Metallurgy and Materials "Metal 2011", 18-20 May 2011, Brno, Czech Republic, 853-859.

Pujatti, M.; Suhadolc, M.; Piculin, D. 2014. Fretting-initiated fatigue in large bore engines connecting rods, Procedia Engineering 74: 356-359.

http://dx.doi.org/10.1016/j.proeng.2014.06.279 
Scialpi, A.; De Filippis, L. A. C.; Cavaliere, P. 2007. Influence of shoulder geometry on microstructure and mechanical properties of friction stir welded 6082 aluminium alloy, Materials \& Design 28(4): 1124-1129.

http://dx.doi.org/10.1016/j.matdes.2006.01.031

Shenoy, P. S. 2004. Dynamic Load Analysis and Optimization of Connecting Rod: MSc thesis. University of Toledo. 190 p.

Yu, Z.-W.; Xu, X.-L. 2015. Fatigue fracture of truck diesel engine connecting-rods, Journal of Failure Analysis and Prevention 15(2): 311-319.

http://dx.doi.org/10.1007/s11668-015-9934-7

Žvinys, J.; Kandrotaitė Janutienė, R.; Meškys, J.; Juzėnas, K. 2012. Investigation of thermo mechanical effect on structure and properties of aluminium alloy 6082, Machines, Technologies, Materials 6(9): 3-6. 